\title{
Pushing Active Learning Into Assessment With a Genetics Escape-Room Final: Gamification to Develop Team Skills in STEM, on Ground and Online
}

\author{
Gaia Bistulfi \\ D'Youville
}

Upper-level, undergraduate STEM courses, which often integrate several disciplines, turn comprehensive finals from assessment tools into torturous hurdles. To extend the benefits of active learning to assessment, we transformed a comprehensive, 300-level Genetics final into a team-based escape room, operable both on ground and online. Quantitative and qualitative data support that this gamification and mastery-based approach in biology significantly improved students' team skills, problem solving ability, courage to speak up, leadership, eased their stress, and furthered student learning while remaining a valuable assessment tool. A detailed description of student activities is presented for generalization of exam gamification to other STEM disciplines.

Keywords: gamification, team skills, active learning final exam, escape room final, STEM, problem solving, pedagogical assessment, leadership, communication, stress reduction, URM, peer learning, undergraduate, final exam, STEM final exam

\section{INTRODUCTION}

Active learning increases student performance (Freeman, 2014) and narrows achievement gaps for underrepresented students (Theobald, 2020) in STEM. In order to maximize benefits for underrepresented minority (URM) students, it is important to implement inclusive pedagogical practices by engaging in conversations and discussions about diversity, equity, and inclusion (Johnson, 2019). A sense of belonging is also important for student engagement and retention (Johnson, 2012). When classroom activities encouraged students to draw connections between the curriculum and real-world experiences and actively engage in teaching and learning, students, and particularly URMs, were reported to be more confident in their academic abilities and more enthusiastic about the course content (Perna, 2009). The use of active learning was advocated to teach students to "think like a researcher" (Kober, 2014).

We theorized that these concepts could be applied not only to teaching but also to assessment and tested this idea by transforming a comprehensive, 300-level Genetics final into an escape room.

Traditional final exams present questions and problems aimed at assessing student mastering of specific learning objectives. Students answer questions, when able, correctly or incorrectly, and receive a corresponding grade. This assessment type is adequate for lower-level courses that focus on the bottom levels of Bloom taxonomy: remember, understand and, depending on the instance, apply. However, this model is less effective for higher level STEM courses, which focus on Bloom's taxonomy higher levels: analyze, evaluate, and create. Problem solving in STEM, like diagnosing in the health profession, is a collaborative process of trial and error that often requires fine tuning and multiple attempts. STEM 
problems often require students to integrate knowledge from different disciplines. For example, genetic problems often require algebra, statistics, chemistry, biology, in addition to genetics-specific content. It is paramount that we teach our students to ask for help, collaborate, and persist in troubleshooting until an effective solution is found and put in place. Professionally speaking, a blank or wrong answer is not an option. Hence, we set out to transform our final exam to respond to the needs of our students and the STEM workforce.

Specifically, we chose to transform our final into an escape room, based on an exciting preliminary report, suggesting that gamification might be a potential high-impact practice to improving retention in STEM fields (Ortiz, 2016). "Gamification," defined as the use of game design elements in non-game contexts (Deterding, 2011) was first introduced in the computer science field. A systematic review of the use of gamification as a learning tool in STEM in higher education reported that gamification increased student engagement and therefore success. However, as the authors themselves point out, the limited body of research is largely confined to the computer science field. The authors suggest additional studies are needed to explore the use of gamification in other STEM fields such as biology (Ortiz, 2016). A more recent study indicates that game-based experiences piqued youth's interest in math and engineering (Gilliam, 2017).

Intrigued by the idea of gamification, we theorized that this approach would be helpful not only to increase student engagement, but also to ease stress at the time of assessment, to develop persistence, problem solving skills, team skills, and further pedagogy.

Teamwork is essential for research, diagnosing, and troubleshooting. STEM graduates join the workforce and may find themselves in research teams, sales teams, or education, where the ability to communicate effectively, raise doubts, and ask poignant questions is a strong determinant of their ability to succeed (Hund, 2018).

While team-skill education in the health professions received exponential attention in the past two decades, mostly focusing on inter professional simulations (Fox, 2018), STEM undergraduate team skills pedagogy is still in its infancy. Common group activities in science, like small research assignments followed by presentations, tend to showcase extroverted individuals without necessarily fostering effective communication and leadership. Typically, we assess the result of group work (a poster or presentation, for example) rather than team interactions and contributions that resulted in the final product. Often, one or two students skilled in the task at hand do most of the work, flattening the learning curve for all involved and generating resentment. In our classrooms, we ask students to raise their hands and speak up without teaching them how to gain the confidence to do so or its importance. Solomon Asch's famous conformity experiments demonstrated that, when in disagreement with a group, most individuals would not speak up, succumbing to peer pressure in agreeing with a blatantly wrong answer (Asch, 1948). These findings were more recently reviewed and reproduced in an online environment (Pierguidi, 2019). This is most alarming in STEM, where it is essential that possible errors be reported as soon as suspected.

We tested our Genetics escape-room final for four consecutive semesters, on a total of forty-three students, on ground (one semester pre-pandemic) and online (three semesters). Through qualitative and quantitative analysis, we found that this approach significantly increased students' confidence in their problem solving skills, team skills, leadership, and ability to speak up. Interestingly, it also furthered students' knowledge and understanding of the subject matter at hand.

We believe that STEM educators will benefit from adapting and applying a similar gamification approach to partial and comprehensive exams in their disciplines, transforming them from mere assessment to powerful pedagogical tools. Our objective is for this paper to act as a first guide for more educators to explore and refine. To this end, the paper is organized as follows. We will present the theoretical framework used to design the activities. Then we will present the activities organized on a timeline and matched to the objectives they help carry out, followed by a detailed description of each objective. In this section, we will also explain in detail the structure and grading of the escape room, so that others may adapt this model to their pedagogical needs. We will then present quantitative and qualitative data assessing results and comparing the escape room final, online and on ground, to traditional finals. When possible, results will be also analyzed for URM students in particular, given the pressing need to increase their presence in the 
STEM workforce. The paper will conclude by highlighting the advantages and disadvantages of an escape room final gamification approach, discussing recommendations for other STEM educators.

\section{FIGURE 1 \\ THEORETICAL FRAMEWORK}

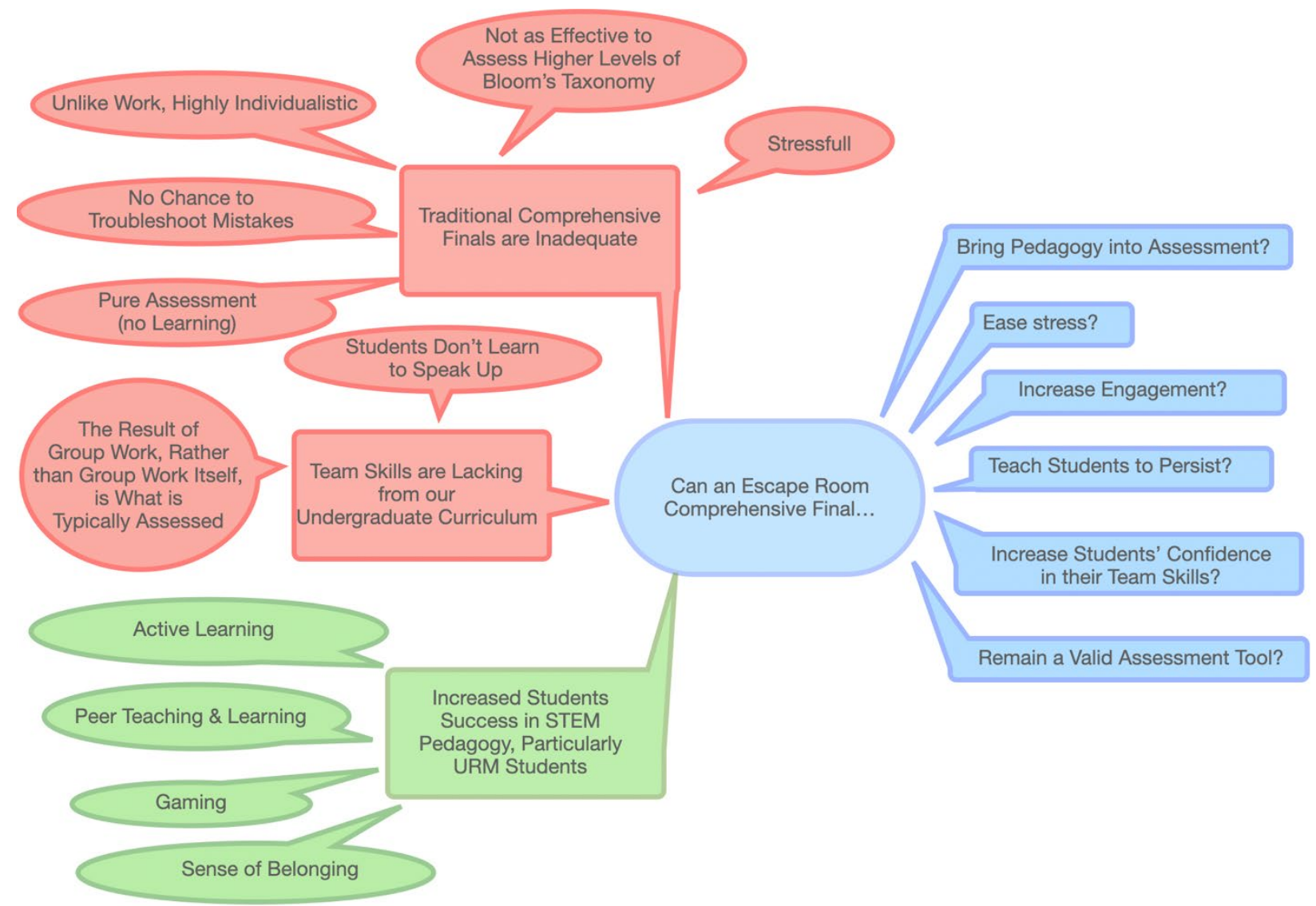

\section{ACTIVITIES}

Ten activities were separated into "Preparatory Activities," which took place before the final exam, and "Final Exam" activities. Preparatory Activities were organically separated over two fifty-five-minute periods, (stopping when out of time to resume the next class period), while the final exam took place in a three-hour block during finals week.

Each activity can be adapted to specific disciplines inside and outside of STEM. However, it is important to deconstruct the more traditional, unidirectional teacher-student dynamic to establish the collaborative climate typical of active learning, which is closer to what students will encounter professionally. 


\title{
FIGURE 2 \\ ACTIVITIES
}

\section{PREPARATORY ACTIVITIES}

\section{FINAL EXAM}
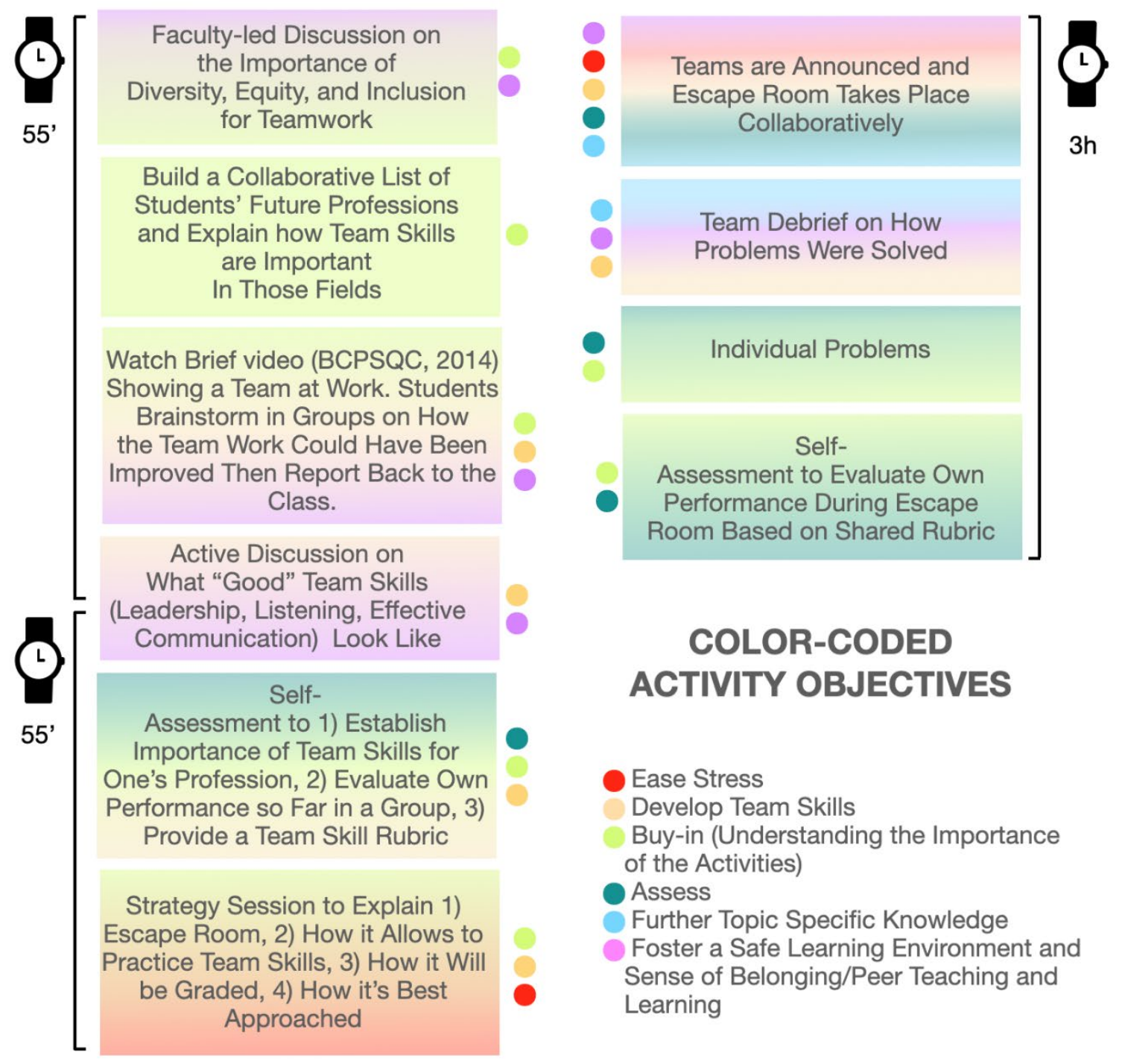

\section{COLOR-CODED ACTIVITY OBJECTIVES}

\author{
Ease Stress \\ Develop Team Skills \\ Buy-in (Understanding the Importance \\ of the Activities) \\ Assess \\ Further Topic Specific Knowledge \\ Foster a Safe Learning Environment and \\ Sense of Belonging/Peer Teaching and \\ Learning
}

\section{Activity Objectives}

Buy In: Understanding the Importance of the Activities

Any successful pedagogical strategy requires student engagement. For students to engage in the activities, they have to "buy in," which means understanding which skills they will gain from the activities and how those skills will serve them professionally. This was first achieved during the very first discussion on equity, diversity, and inclusion, when students were reminded that the ability to speak up as well as listen to others are instrumental for any team to thrive (see next objective). Buy in was consolidated when students 1) Considered how team skills would apply to their specific career of choice, 2) Approached critically a short video (BCPSQC, 2014) showing the disastrous consequences of poor teamwork, 3) Defined what "good team skills" looked like to them in terms of leadership, active listening, effective communication, and compassion, 4) Learned how the escape room would allow them to practice the new team skills they had collaboratively defined, 5) Learned that their team skills would be assessed during the final and incorporated in their grade, 6) Self-assessed their own abilities by selecting all behaviors that 
applied in a questionnaire derived from the Teamwork VALUE Rubric (Rhodes, 2014) (FIGURE 3), before and after the escape room, 7) Self-assessed their skills on a scale of one to ten, based on their own behavior during the activities, before and after the escape room.

\section{FIGURE 3 SELF-ASSESSMENT QUESTIONS DERIVED FROM TEAMWORK RUBRIC}

Did you contribute to discussions? Mark everything that seems appropriate.

No, I didn't speak up

I spoke up but said things in hindsight were not helpful

Some of my suggestions were helpful

At least in one instance I offered a helpful suggestion that built on somebody else's idea

I helped the team by articulating merits of different ideas

To which extent did you help foster a constructive team climate? Mark all that applies.

After reading all the answers below, I guess I didn't.

I treated team members politely and respectfully.

I used positive vocal or written tone, facial expressions, and/or body language to convey a positive attitude about the team and its work

$\square \quad$ I motivated team-mates by expressing confidence about the importance of the task and the team's ability to accomplish it

$\square \quad$ I provided assistance and/or encouragement to team members.

Did you facilitate the contribution of other team members? If yes, how? Mark everything that seems appropriate

$\square \quad$ I tried but had a hard time listening and interrupted others often

I made sure to never interrupt and listen to others

$\square \quad$ I never interrupted and re-stated other people's points asking for clarifications when needed other people's point

I built upon other people's contributions by summarizing their point and adding to them

I built upon other's contributions and invited other members to participate when I noticed they were not talking

How did you respond to conflict? Mark all that applies

$\square \quad$ I struggled with alternative viewpoints and felt defensive. My behavior might have gotten in the way of progress

I accepted alternative viewpoints passively (I went with the flow)

I tried to steer the team away from conflict and back to common ground

I recognized the conflict and stayed engaged with it

I addressed the conflict constructively, helping to solve the issue and strengthening the team.

Fostering a Safe Learning Environment/Peer Teaching and Learning

Diversity is essential for evolution and the survival of the species. Unique ideas come from individuals with unique backgrounds, and it is the responsibility of any good leader to ensure no idea goes unheard or even unuttered. Individuals are unique blends of cultural backgrounds, sexual preferences, gender identification, economic status, trauma, privilege, and much more. It is paramount for students to understand that it is indeed difficult to speak up, for some more than others, and that this is a skill that can be honed with time. Human nature resists change; as scientists, it is our responsibility to advocate for change when needed, identifying and deconstructing our own biases and prejudices to choose the best idea 
presented to resolve an issue. Students are asked to reflect on the composition of their unique identity and to recall one or more instances were a seemingly harmless comment left them feeling hurt. Occasionally, students will be comfortable sharing their experiences. Other times, faculty can bring up pedagogically relevant examples, possibly not only of "being hurt" but also of "unwittingly hurting" someone else and making amends. It is important for the faculty to acknowledge that our ignorance will always outweigh our knowledge, and that it is essential to make amends when unwittingly being offensive, starting from faculty. Acknowledging the inherent value of our differences and the challenge of dissent by discussing Asch's conformity experiments is a good start to foster a collaborative, safe environment where student dare to speak up. For these reasons, this faculty-led discussion is the very first activity on the timeline. Students are reminded that one of the priorities stemming from this series of activities is to maximize everyone's comfort to enable the sharing of ideas. Students are asked to pay attention to body language and to invite opinions from quieter students. These inclusion techniques will be practiced during successive brainstorming sessions, active discussions, the escape room itself, and the debriefing activity, where students will teach to each other how the problems were solved.

\section{Develop Team Skills}

Students engage in brainstorming and active discussions, first in small groups, online we used Zoom breakrooms (Yuan, 2011), and then reporting to the entire class and faculty. Next, they self-assess a first time based on their behavior during the discussion, ranking themselves on a scale from one to ten on the skills they collaboratively defined. Additional questions derived from the Teamwork VALUE Rubric (Rhodes, 2014) (FIGURE 3) allow students to select their behaviors and identify what optimal performance would look like, providing a frame of reference and goals. Faculty explained during discussions how frustration is normal under pressure and how learning to manage it is an important part of professional development. On the day of the exam, students choose tactical strategies and collaborate to solve the escape room, working to improve whichever weaknesses they had pinpointed in their team skills. At the end of the escape room, students debrief, explaining to each other how each problem was solved. This is essential for students to learn to ask for help as they take turns in listing problems they did not completely understand. Finally, students self-assess a second time, evaluating their behavior during the escape room.

\section{Easing Stress}

Stress management is important for any profession. However, students are often exposed to unhealthy levels of pressure, specifically during finals week. This was exacerbated during the COVID-19 pandemic. We eased students' stress by explaining in detail what to expect from this novel type of exam: the structure of the escape room, the type of locks implemented, and how their performance would be graded. In particular, students were reminded that an incorrect answer would result in a lock not opening without further penalty, allowing students to rework problems until they knew the correct, full-credit answer. The collaborative nature of the escape room, with students divided in teams of four or five, reassured students they would not be alone, should they forget something. The ability to ask for hints for a small penalty during the escape room also reassured students they would not remain stuck. It is important to point out how an easier exam, per se, would not be successful, as it would not effectively assess student learning objectives and it likely would be perceived as a waste of time.

\section{Further Topic Specific Knowledge}

Exams, traditionally, are confined to assessment. However, the escape-room format allows to further pedagogy by 1) Giving students multiple attempts at solving problems, similarly to the mastery-based approach found successful in mathematics, and by 2) Allowing students to debrief with the rest of their team to review how each problem was solved in light of having to face each problem type, potentially, in the individual assessment. 
Assess

Students self-assess their team skills before and after the escape room. Their selections bear no weight on their grade. Faculty independently assess students' team skills during the unfolding of the escape room. Topic-specific knowledge is assessed by reproposing variations of the most difficult problems presented during the escape room during the "Individual Problems" portion of the final exam.

\section{The Final Exam}

The Escape Room

Our "escape room" is a self-contained system of two nesting boxes purchased from Breakout EDU (Breakout EDU, n.d.). The external box is locked by a hasp with three locks, while the inner box is locked by a hasp with six locks for a total of nine locks, either alphanumeric or with symbols. Students are provided with a UV light and allowed scientific calculators and scrap paper. Clues and problems are loose inside the box or taped outside. In particular, one is taped to the bottom of the outer box, which means students have to think to turn the box around to find it. Faculty agree with students in keeping two significant figures after the decimal point and in notifying students when lock won't open because of an approximation difference (as opposed to an incorrect procedure). Questions can be explicit, in invisible ink, or presented as riddles. Each lock is identified by a small image that connects it to a problem. While some question/lock connections are obvious, other require students to brainstorm. The inside of the inner box, accessible only after all nine locks are open, contains a little reward, as simple as a big printed "Congratulations!" or, when in person, friendship bracelets. Online, the escape room is conducted via Zoom; all materials (boxes, UV lights) are at the faculty end, visible to students thanks to a document lamp. Student watch, discuss, and direct faculty's actions around the escape room. Both online and on ground, faculty supervises the escape room, taking notes on students' behavior and contributions, and providing "hints," as requested, at the cost of $1 \%$ each over the final grade.

For the escape room to work, it is important that teams are devised by faculty, to maximize diversity and to be as balanced as possible. Also, teams are announced at the time of the exam to ensure everyone reviews the entire semester (as opposed to dividing chapters among teammates). It is important to explain the rationale for these choices and how they will benefit the students during the strategy session.

The escape room typically takes about an hour. Some teams finish faster, while some take as long as ninety minutes. To ease stress, it is important to remind students that time will not be a limiting factor: three hours are more than enough to complete the escape room.

\section{Debrief}

Students are allowed a five-minute break to go to the restroom or have a snack. Then they partake in a ten-minute debrief under faculty supervision. The time limit, more to keep pace, is rarely enforced, and extra time can be allotted as needed. Some teams complete the debrief in five minutes while others take as long as fifteen. Again, faculty supervises the debriefing sessions, noting students' behavior and interactions.

\section{Individual Problems}

Next, each student is given three problems to solve on their own in thirty-minute time (longer for students with learning disabilities). The problems are similar to some of the ones presented in the escape room, but never identical, and typically require the students to engage in complicated, multi-step thought processes. For example, a student might be provided with a quantitative genetics problem that requires them to 1) Correctly perform genetic crosses for two generations, coming up with nine separate genotypes and their frequency in the F2, 2) Correctly calculate production of each genotype based on additive genetics principles, 3) Calculate how many individuals in the F2 would have specific productions, 4) Calculate production average by listing formula and calculations, 5) Calculate production variance by listing formula and calculations, 6) Calculate production standard deviation by listing formula and calculations. Standard deviation, if correct, will open the corresponding lock. Other examples, for Genetics acolytes, may include deriving the interference from a three-point testcross, or calculating a Chi Square value. 


\section{Grade}

The grade was broken down as follows: 3\% Pre-Escape-Room Self-Assessment, 3\% Post-EscapeRoom Self-Assessment, 54\% Escape Room (6\% per lock), 10\% Team Skills Demonstrated During Escape Room, 30\% Individual Problems. Hints from faculty cost 1\% each.

Giving minimal points to the pre- and post-assessment motivated students to submit them without excessively inflating the grade. It is important to note that students were allowed to skip questions or submit blank surveys for credit as an opt-out method.

Each of the nine problems presented in the escape room was worth six percent of the final grade. This meant that struggling students could get a sixty percent, our minimum passing grade, by completing the self-assessment as well as the escape room with their team. Advantages and disadvantages of this approach will be discussed later.

Ten percent of the grade came from applying team skills during the activity, as observed by the faculty member. Snapping at a teammate in frustration would cost points, but not as many if the students caught themselves and apologized. Speaking up, building on teammates' ideas, helping others to understand, seeking opinions, active discussion, asking for help when needed, coming up with breakthroughs would gain points as explained to students during the strategy session. This motivated students in engaging in positive team behaviors decreasing self-consciousness.

The remaining thirty percent of the grade was determined by the three individual problems. Students were informed during the strategy session that at any point during the escape room, if stuck, they could ask for a hint. Each hint would cost the team one percent over the final grade. Students rarely used this option, which is more a failsafe to ease their minds.

\section{RESULTS}

\section{Demographics}

Forty-three students took the escape-room final over four semesters. The first group (Fall 19) was the only one that took the escape final on ground. The next three groups (Spring 20, Fall 20 and Spring 21) attended the lecture on Zoom and completed the escape room online. Of these forty-three students, fourteen (thirty-three percent) were URM, three identified as LGBTQIA2+, and three were adult learners with children. This is likely to be an underestimate of the diversity in the class because students were not formally asked to identify themselves as a minority.

\section{Students Valued Team Skills}

The data presented (FIGURE 4) reflects ratings (average \pm standard deviation) from the ten students who attended the 2021 spring semester. Data was not compounded with previous semesters because not all categories had been assessed, and some students misunderstood the question and rather than evaluating the importance of the skills, they self-assessed twice. However, the data is telling and representative of trends observed in previous semesters. 
FIGURE 4

STUDENTS VALUED TEAM SKILLS

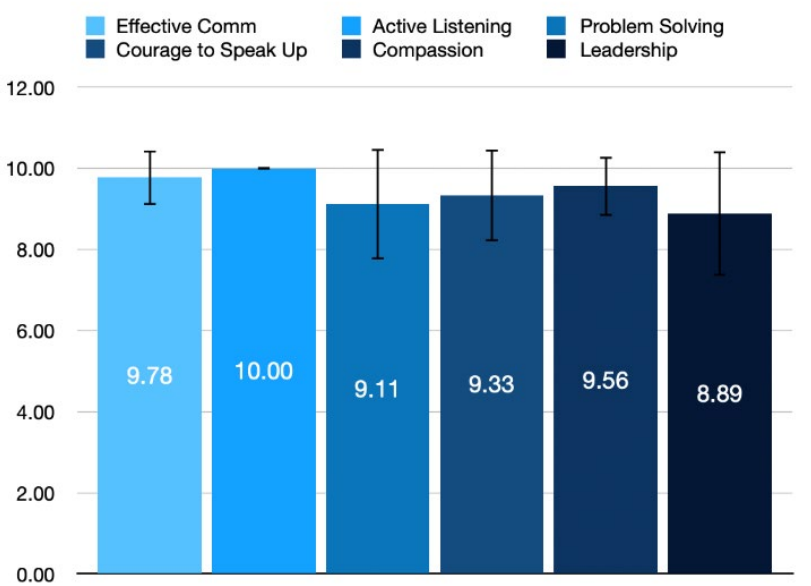

\section{The Final Escape Room, Online and on Ground, Significantly Increased Students' Confidence in Their Team Skills}

Students self-assessed their ability to 1) Communicate effectively, 2) Listen actively, 3) Problem solve, 4) Speak Up, 5) Be compassionate, 6) Be leaders, before (pre) and after (post) the escape room, on a scale from 1 (not able at all) to 10 (perfectly able). Interestingly, students did not necessarily remember what they had chosen in their pre-assessment when completing the post-assessment. The data (FIGURE 5) presents average ratings \pm standard deviations over forty-three students. No significant difference was found comparing data from the on-ground escape room with the online ones (data not shown). Statistical significance was calculated using a two-tails, paired T-Test. Students reported a statistically significant increase in all team skills assessed. Separate analysis focusing on either URM students or all minorities, despite the smaller sample size, found significant increases in all categories, although the p-value was often higher as compared to non-minority students.

\section{FIGURE 5}

\section{THE ACTIVITIES SIGNIFICANTLY IMPROVED STUDENTS' TEAM SKILLS}

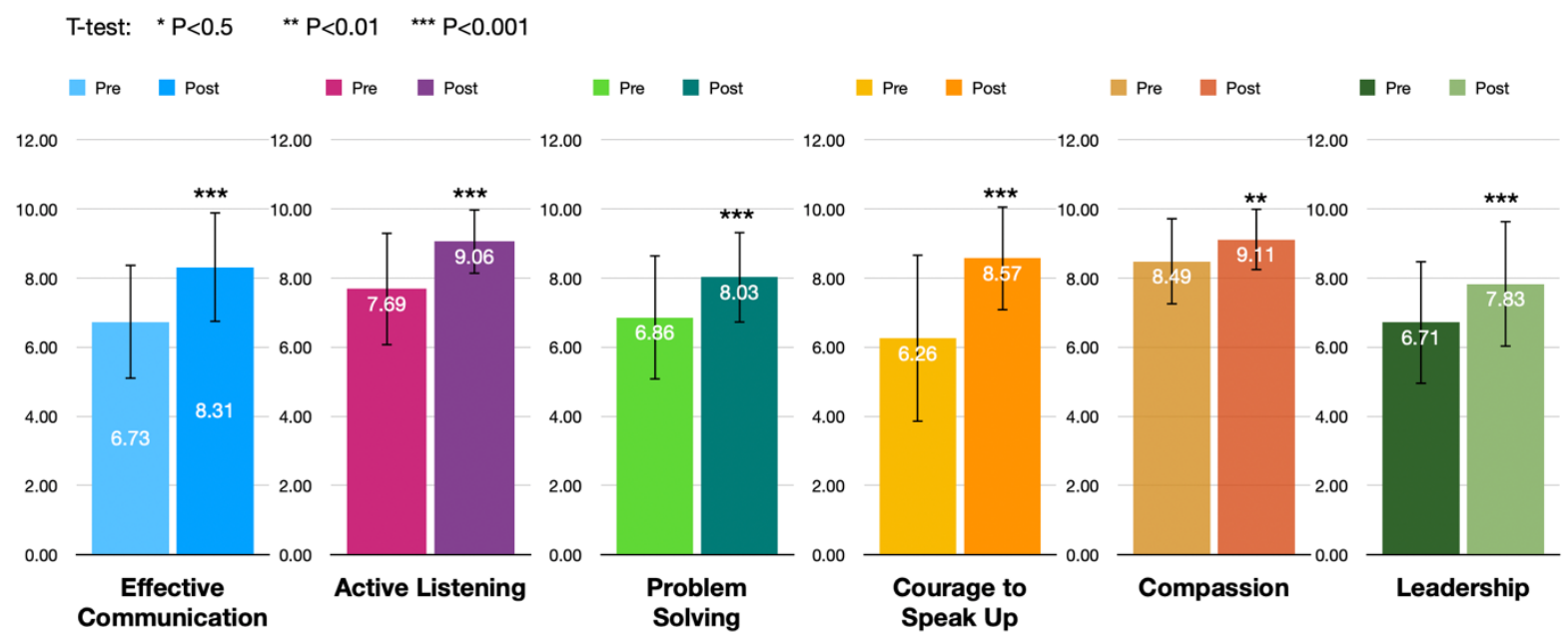




\section{The Final Escape Room Is Easier Than Traditional Comprehensive Final}

The escape-room final makes it almost impossible for a student to score less than sixty percent on their final. This was clearly not the case on the traditional comprehensive final. The Genetics course, among other forms of assessment, has three partial exams. We compared the average grade of the three partials against the grade on the final to assess the difficulty of final exams, in different formats, as compared to partials. FIGURE presents the ratio between the average partials (numerator) and the final exam (denominator). When the ratio is one, this means the student received a similar grade in their final exam as compared to the average grade in the three partials. A ratio above one meant the final grade was lower than the partials, while a ratio below one meant the final grade was higher than the partials. The black bars represent the average ratio \pm standard deviation in each group. The dots in the graph represent individual students' ratios: the left group represent grades from fifty-seven students across three different semesters (spring 18, fall 18, spring 19) who took the traditional paper comprehensive final; their ratio was slightly higher than one. The middle group and right group are ratios from students who took the escape-room final, either on ground (middle group), or online (right group). The three groups were compared by two-tails, two-sample equal T-Test. There was no significant difference between escape-room ratios on ground and online ( $\mathrm{p}=0.994)$. However, the escape-room final, both on ground and online, was significantly easier. The impact of this findings will be discussed in the conclusion. There was no significant different when comparing ratios for URM students against ratios for non-URM students, on ground or online, with the traditional final or the escape room.

\section{FIGURE 6 \\ THE ESCAPE-ROOM FINAL IS EASIER}

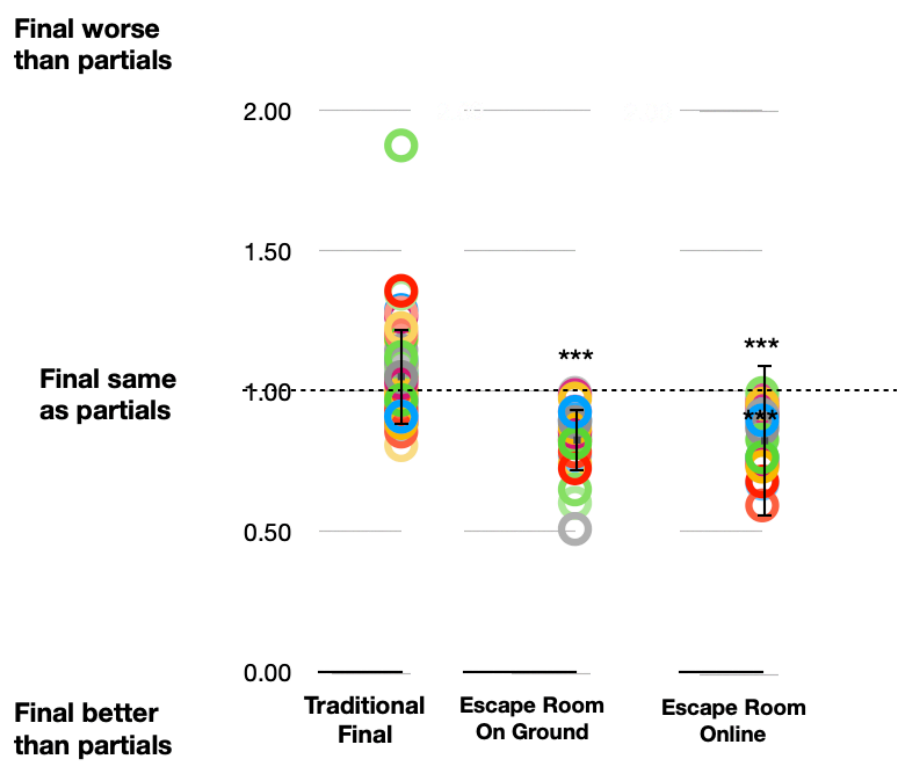

\section{The Escape-Room Final Has Pedagogical Value, Eases Stress, and Fosters Relationships Among Students}

On the post-escape room assessment, students are given a blank space to leave optional comments, positive or negative, about their experience doing the escape room. The comment was not guided as we did not ask any specific question. We analyzed the comments for common threads.

Out of the twenty-five students who left a comment, sixteen said the escape room was "fun" or "great." Sixteen were excited they had learned team skills valuable for their future chosen profession. Thirteen commented on how the team approach eased their "stress" or "anxiety." Eight separate students commented on how the escape room presented an additional opportunity for them to understand Genetics concepts they 
had not mastered prior to the final. Specifically, one student wrote how "Listening to them [the other students] explain the problem in a 'student voice' was much better to understand the material for me." It is interesting to observe than on a traditional final only about twenty percent of the students would complete correctly the multi-step, quantitative genetics problem ending with the calculation of standard deviation, but after the escape room, about seventy percent of the students received full credit. Notice that this is not the type of problem a student can memorize without understanding. Seven students mentioned that the escape room was still a challenging exam. Five students found that the escape room and the interaction with their peers boosted their confidence. One student wrote, "Daunting to admit to my peers that I was confused but relaxed right away when I realized they were confused too!" Four students mentioned how the escaperoom format was so memorable they would remember topical content (e.g. epistasis or three-point test crosses) for a long time to come. Three students mentioned how the escape room made them more aware of their actual skills. Four students appreciated how the format still forced them to review the entire semester of coursework, three students found the group allowed them to solve problems they would have never mastered on their own, and two students reported how they'd finally talked to classmates they'd never said a word to the entire semester. One student mentioned that the online format made it hard to understand some of the questions because they had unstable internet connection.

\section{CONCLUSION}

Transforming a comprehensive final into an escape room has allowed us to bring active learning into assessment and to add team-skill pedagogy to our curriculum. Our Genetics escape-room comprehensive final shows that gamification is a valuable tool in biology. The unique setup with locks that open only with the correct answer allows for a mastery-based approach, which was already demonstrated to be effective in math. Here, students practice persistence and troubleshooting while engaging with each other to discuss possible approaches and solutions.

Students not only learn from engaging repeatedly with the problems, but they also learn from having to explain their ideas and approaches to their peers, often finding mistakes in a collaborative manner. Peer teaching and learning is maximized during the debriefing activity, when students explain to each other how problems were solved. Personally, I feared the strongest student in each team would end up tutoring the rest, but this has never been the case. While often one student moderated the debrief by asking who else had questions or if anyone struggled with a specific problem, different students took turns in explaining procedures. Probably in light of discussions about inclusion, students were excellent at contributing, even if only small bites to each problem, eager to help and involve each other. The debriefing was also the activity were students truly learned to ask for help, pointing out problems they had not understood to ensure they grasped the procedure before facing it, alone, in the individual problems.

If we want our graduates to speak up, lead, be collaborative, inclusive, respectful, and resilient we have to teach them how by providing them with rubrics, strong rationales, modeling behaviors, and allowing them to practice. Professionally, problem solving does not stop at the wrong answer. We have to teach our students to collaborate, ask for help, and tackle problems until solved. Organizing a rubric as multiplechoice questions, made it easy for students to see where they were and where they wanted to be, providing positive models of behavior. For example, students who initially rank themselves highly in effective communication may find themselves lacking when selecting from the multiple choice that they expressed their ideas but did not build on others' suggestions nor invited quiet individuals to join the conversation. They now have clear, actionable steps toward improvement, and a stage to practice: the escape room. Grading team skills during the escape room, no matter how small the portion of the grade, motivates students to try: the occasional frustrated reaction is followed by apologies, introverts awe the group with their well-hidden brilliance, hesitance decreases, extroverts listen, weak students learn and take pride in contributions they didn't know they could offer, strong students teach and are humbled to learn, relieved to admit they did not know some answers. Students pay attention to the group in a new light: are they the one talking all the time? Who isn't talking at all? Are they building on others' ideas when talking? They encourage each other and discovere that indeed answers come from the most unexpected places: joking 
with each other, helping someone through a mistake, brainstorming, prodding the student who has yet to utter a word and turns out to be a genius.

Students' stress is eased thanks to the team approach, which makes the final exam experience "great," "fun" and "memorable." Students report significantly increased confidence in all the team skills we assessed: leadership, courage to speak up, active listening, compassion, problem solving, and effective communication.

The one potential pitfall of the escape-room final is that it is indeed easier than a traditional final. Nonetheless, grade inflation can be averted by weighing the final accordingly. For example, the comprehensive final could be worth only five of ten percent of the overall grade. This approach will ensure that the final won't "make or break" students on their very final assessment. On the contrary, it will provide a memorable experience that, while still forcing students to review a semester worth of material, provides a further chance at learning the course material as well as additional valuable skills.

Gamification of final exams via building a thematic escape room has been a successful approach that can be easily adapted from Genetics to any subject with an intense problem solving component, inside and outside of STEM. Materials (two boxes, nine locks, two hasps, UV light, and invisible ink pen per each group) are relatively affordable and durable. Development of the escape room is at first labor intensive, but once established, the setup is versatile and quick to change, semester after semester, and provides invaluable advantages with regards to student engagement and learning.

\section{REFERENCES}

Asch, S.E. (1948). The doctrine of suggestion, prestige and imitation in social psychology. Psychological Review, 55(5), 250-276. doi:10.1037/h0057270

BCPSQC. (2014, November 21). How well does your team communicate? [Video file]. Retrieved from https://youtu.be/gp9x3fvKjm4

Collins, J.B., Harsy, A., Hart, J., Haymaker, K.A., Hoofnagle, A.M., Janssen, M.K., . . OShaughnessy, J. (2019). Mastery-based testing in undergraduate mathematics courses. Null, 29(5), 441-460. doi:10.1080/10511970.2018.1488317

Deterding, S., Sicart, M., Nacke, L., O’Hara, K., \& Dixon, D. (2011, May 7). Gamification using gamedesign elements in non-gaming contexts. Paper presented at the 2425-2428. doi:10.1145/1979742.1979575

Fox, L., Onders, R., Hermansen-Kobulnicky, C.J., Nguyen, T.N., Myran, L., Linn, B., \& Hornecker, J. (2018). Teaching interprofessional teamwork skills to health professional students: A scoping review. Journal of Interprofessional Care, 32(2), 127-135. doi:10.1080/13561820.2017.1399868

Freeman, S., Eddy, S.L., McDonough, M., Smith, M.K., Okoroafor, N., Jordt, H., \& Wenderoth, M.P. (2014). Active learning increases student performance in science, engineering, and mathematics. Proceedings of the National Academy of Sciences of the United States of America, 111(23), 8410-8415. doi:10.1073/pnas.1319030111

Gilliam, M., Jagoda, P., Fabiyi, C., Lyman, P., Wilson, C., Hill, B., \& Bouris, A. (2017). Alternate reality games as an informal learning tool for generating STEM engagement among underrepresented youth: A qualitative evaluation of the source. Journal of Science Education and Technology, 26(3), 295-308. doi:10.1007/s10956-016-9679-4

Hund, A.K., Churchill, A.C., Faist, A.M., Havrilla, C.A., Love Stowell, S.M., McCreery, H.F., . . . Scordato, E.S.C. (2018). Transforming mentorship in STEM by training scientists to be better leaders. Ecology and Evolution, 8(20), 9962-9974. doi:10.1002/ece3.4527

Johnson, D.R. (2012). Campus racial climate perceptions and overall sense of belonging among racially diverse women in STEM majors. Journal of College Student Development, 53(2), 336-346. doi:10.1353/csd.2012.0028

Johnson, K.M.S. (2019). Implementing inclusive practices in an active learning STEM classroom. Advances in Physiology Education, 43(2), 207-210. doi:10.1152/advan.00045.2019 
Musavi, M., Friess, W.A., James, C., \& Isherwood, J.C. (2018). Changing the face of STEM with stormwater research. International Journal of STEM Education, 5(1), 2-2. doi:10.1186/s40594018-0099-2

National Research Council. (2015). In N. Kober (Ed.), Reaching students: What research says about effective instruction in undergraduate science and engineering. Washington, DC: The National Academies Press. doi:10.17226/18687

National Research Council; Division of Behavioral and Social Sciences and Education, Board on Science Education, \& Kober, N. (2014). Reaching students. Washington, D.C: National Academies Press. doi:10.17226/18687

Ortiz Rojas, M.E., Chiluiza, K., \& Valcke, M. (2016). Gamification in higher education and stem: A systematic review of literature. doi:10.21125/edulearn.2016.0422

Perna, L., Lundy-Wagner, V., Drezner, N.D., Gasman, M., Yoon, S., Bose, E., \& Gary, S. (2009). The contribution of HBCUS to the preparation of African American women for stem careers: A case study. Research in Higher Education, 50(1), 1-23. doi:10.1007/s11162-008-9110-y

Pierguidi, L., Guazzini, A., Imbimbo, E., Righi, S., Sorelli, M., \& Bocchi, L. (2019). Validation of a lowcost EEG device in detecting neural correlates of social conformity. Annual International Conference of the IEEE Engineering in Medicine and Biology Society. IEEE Engineering in Medicine and Biology Society. Annual International Conference, 2019, 3131-3134. doi:10.1109/EMBC.2019.8856716

Rhodes, T. (2014). Assessing outcomes and improving achievement: Tips and tools for using rubrics. Peer Review: Emerging Trends and Key Debates in Undergraduate Education, 16(3), 32.

Theobald, E.J., Hill, M.J., Tran, E., Agrawal, S., Arroyo, E.N., Behling, S., . . Freeman, S. (2020). Active learning narrows achievement gaps for underrepresented students in undergraduate science, technology, engineering, and math. Proceedings of the National Academy of Sciences of the United States of America, 117(12), 6476-6483. doi:10.1073/pnas.1916903117

White, W. (2020). Breakout EDU. Retrieved from https://platform.breakoutedu.com

Yuan, E. (2013). Zoom. [Computer Software]. Zoom Video Communications Inc. 